\title{
Wind tunnel test study on the influence of railing ventilation rate on the vortex vibration characteristics of the main beam
}

\author{
Xin $\mathrm{Cui}^{{ }^{*}}$, Liang $\mathrm{Gao}^{2}$, Jian X. $\mathrm{Liu}^{3}$ \\ ${ }^{1}$ School of Civil Engineering and Communication, North China University of Water Resources and Electric Power, China, \\ Zhengzhou \\ ${ }^{2}$ School of Civil Engineering and Architecture, Xi'an University of Technology, China, Xi'an \\ ${ }^{3}$ College of Highway, Chang'an University, China, Xi'an
}

Corresponding Author Email: 18424878@qq.com

https://doi.org/10.18280/ijht.360109

Received: 20 October 2017

Accepted: 2 December 2017

\section{Keywords:}

bridge engineering, vortex-induced vibration, aerodynamic measure, wind tunnel test.

\begin{abstract}
To study the influence of the railing ventilation rate on the vortex vibration characteristics of the blunt body box girder, the wind tunnel test is carried out by changing the ventilation rate of the lateral railing, and arranging the pressure measuring holes on the surface of the model. The railings are sealed in two ways: in the one-sealed three-open plan, a sealed segment is arranged every three open segments and in the one-sealed two-open plan, a sealed segment is arranged every two open segments. The ventilation rate of two ways was reduced by $25 \%$ and $33 \%$ respectively. Under different ventilation rate conditions, the relationship between the wind speed and amplitude of the main beam section and the wind pressure duration of each measuring point are measured. Then, the changes of average pressure coefficient, fluctuating pressure coefficient and power spectral density with the railing ventilation rate on each measuring point of the model surface are analyzed. The results show that the vortexinduced vibration of the main beam can be effectively suppressed by reducing the railing ventilation rate. However, the sensitivity of the torsional and vertical bending vortex-induced vibration to the railing ventilation rate of is different. When the railing ventilation rate decreases to a certain threshold, the vortex-induced vibration can be effectively restrained.
\end{abstract}

\section{INTRODUCTION}

Vortex-induced vibration is one of wind-induced vibrations which is easy to occur to long-span bridges at low speed wind. Vortex-induced vibration is a kind of amplitude limiting vibration with self-excited property. Although it does not destroy the bridge structure as much as flutter, it has a high frequency at low wind speed, and the amplitude is large enough to influence the traffic safety. Therefore, it is very important to restrain vortex-induced vibration or limit amplitude to an acceptable range during construction or completion stage. At present, the measures to restrain vortexinduced vibration can be divided into structural measures, mechanical measures and pneumatic measures whose parameter analysis have been carried out in literature [1 7]. Conventional pneumatic measures include deflector, flow suppression plate, wind nozzle, rectifier plate, spoiler, splitter plate, stabilizer plate and so on [2]. Although some aerodynamic measures can effectively eliminate or mitigate the vortex-induced vibration phenomenon for bridges [8], some very good measures are often abandoned because they do not meet the design requirements [9]. In fact, the vortexinduced vibration satisfying the standard requirements is allowed in the wind resistant design of long-span bridges [10]. Thus, the exploration of some economical and effective pneumatic measures has become the main work of vortex vibration control for bridges. Although the railing shape has significant influence on the vortex-induced vibration of the main, it is proved by many scholars; however, the railing shape is not always changed at will, because it involves the bridge landscape and so on. In this paper, the influence of the railing ventilation rate on the vortex-induced vibration of blunt body box girder is studied based on a cable-stayed bridge in China, and the vibration suppression mechanism is revealed from the energy level.

\section{TESTING SITUATION [11]}

This experiment was carried out in the CA-1 wind tunnel laboratory in Chang'an University under the background of a cable-stayed bridge under construction. This bridge is a cable-stayed bridge with single cable plane and steel box girder. The section shape of the main beam is shown in Fig. 1, and a segmental model with the scaled ratio of 1:50 was made at the finished stage. The model is $2.2 \mathrm{~m}$ in length, $0.776 \mathrm{~m}$ in width and $0.092 \mathrm{~m}$ in height. Vortex-induced vibration test and surface pressure measurement were carried out.

The rigid body suspension model is used in the vortexinduced vibration test, which is connected with the rigid arm, and the system consisting of the model and the rigid arm is suspended on the inner support alpha structure through 8 springs (Fig. 2). 3 acceleration sensors are installed at both ends of the rigid arm to collect the vibration signals of vertical bending and torsion. The damping ratio of the test model is $0.5 \%$, and the wind speed ratio is $1: 2.5$. The design parameters of the model are listed in Tab. 1. 


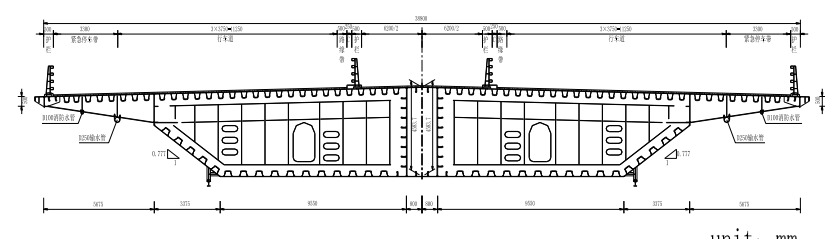

unit: $m m$

Figure 1. Typical cross section of box girder

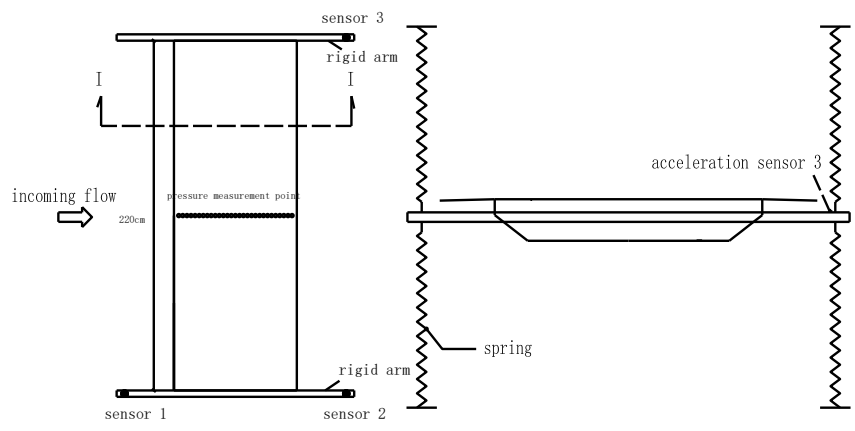

(a) Top view

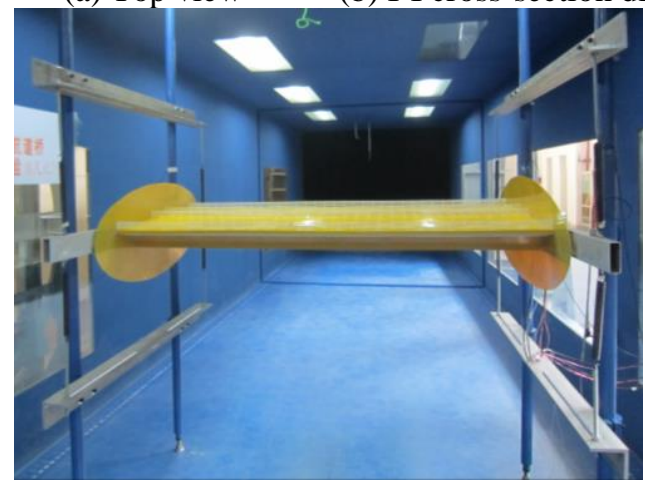

(c) Test model in wind tunnel

Figure 2. Layout of wind tunnel test

Table 1. Parameters of segmental model

\begin{tabular}{cccccc}
\hline Parameter name & Unit & $\begin{array}{c}\text { Actual } \\
\text { bridge } \\
\text { value }\end{array}$ & $\begin{array}{c}\text { Model } \\
\text { design } \\
\text { value }\end{array}$ & $\begin{array}{c}\text { Model } \\
\text { measured } \\
\text { value }\end{array}$ & $\begin{array}{c}\text { Error } \\
(\%)\end{array}$ \\
\hline Equivalent mass & $\mathrm{kg} / \mathrm{m}$ & 35000 & 14.00 & 13.93 & 0.50 \\
\hline $\begin{array}{c}\text { Equivalent mass of } \\
\text { inertia moment }\end{array}$ & $\begin{array}{c}\mathrm{kg} \cdot \mathrm{m}^{2} / \\
\mathrm{m}\end{array}$ & 3630000 & 0.58 & - & - \\
\hline $\begin{array}{c}\text { Fundamental } \\
\text { frequency of vertical } \\
\text { bending }\end{array}$ & $\mathrm{Hz}$ & 0.3373 & 6.75 & 6.67 & 1.19 \\
\hline $\begin{array}{c}\text { Fundamental } \\
\text { frequency of torsion. }\end{array}$ & $\mathrm{Hz}$ & 0.9253 & 18.51 & 18.25 & 1.41 \\
\hline
\end{tabular}

80 pressure taps with an aperture of $1 \mathrm{~mm}$ were set at the $1 / 2$ length of the model which are used to measure the surface pressure of the model. The distribution of these taps is shown in Fig. 3, and $1,2, \ldots 80$ is the number of pressure measuring points in the figure. In the figure 6 to figure 13 , $\mathrm{DD}$ is defined as follow: if the distance of a pressure measuring point from upstream point $\mathrm{A}$ is Ddist, and the distance from the upstream point A to the downstream point $\mathrm{B}$ is Dtotal, then the dimension- distance:

$$
\mathrm{DD}=\frac{\mathrm{D}_{\text {dist }}}{\mathrm{D}_{\text {total }}}
$$

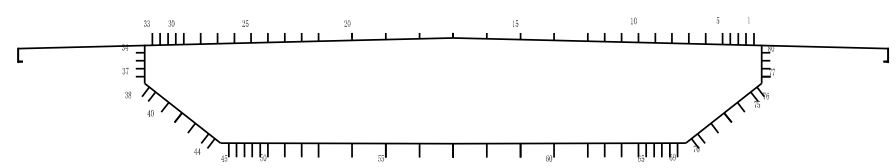

Figure 3. Schematic diagram of pressure taps distribution

In the uniform flow field, the wind tunnel tests are carried out on angles of attack of $+5^{\circ},+3^{\circ}, 0^{\circ},-3^{\circ}$ and $-5^{\circ}$. It is found that the vertical bent vortex-induced vibration occurs at angle of attack of $+5^{\circ}$ and torsional vortex-induced vibration occurs at $-5^{\circ}$. In order to restrain the occurrence of vertical and torsional vortex-induced vibration, the two rows of railings on the outer side of the standard section in Figure 1 are closed. The railings are sealed in two ways: in the one-sealed three-open plan, a sealed segment is arranged every three open segments and in the one-sealed two-open plan, a sealed segment is arranged every two open segments, which are shown in Fig. 4. The vortex-induced vibration test and surface pressure measurement of the two schemes are carried out at $-5^{\circ}$ and $+5^{\circ}$, respectively, and this paper attempts to reveal the influence mechanism of railing ventilation rate on the vortex-induced characteristics of the bridge deck section from the pressure level.

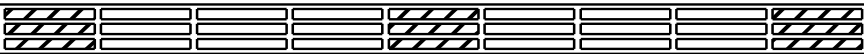

(a) One-sealed three-open plan (a sealed segment is arranged every three open segments)

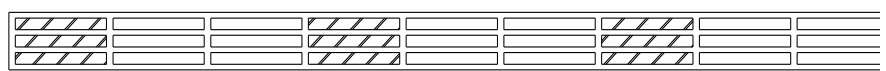

(b) One-sealed two-open plan (a sealed segment is arranged every two open segments)

Figure 4. Schematic diagram of railing closing measures

\section{TEST RESULTS AND ANSLYSIS}

\subsection{Relationship between vortex vibration response and wind speed [12]}

Fig. 5 (a) is the relationship curve between the twist angle and wind speed of the original scheme and the two closed railings schemes at $-5^{\circ}$ angle of attack. The longitudinal coordinate is the standard deviation of the twist angle at the corresponding wind speed. It can be seen from Fig. 5 (a) that a significant torsional vortex-induced resonance at $-5^{\circ}$ appeared in the original scheme. When the actual bridge wind speed is $23.5 \mathrm{~m} / \mathrm{s}$, the torsional angle amplitude is $0.2488^{\circ}$ (the amplitude is $\sqrt{2}$ times of the standard deviation), which does not meet the requirements of "Highway and Bridge Wind-resistance Design Standard". The torsional vortex-induced resonance phenomenon still exists when the one-sealed three-open plan is adopted but the amplitude of the torsional angle decreases to $0.1708^{\circ}$. It is shown that the closed railings can effectively reduce the amplitude of torsional vortex-induced resonance. When the one-sealed two-open plan is used to close the outside railings, the maximum amplitude is only $0.0337^{\circ}$ when the wind 
speed is $24.5 \mathrm{~m} / \mathrm{s}$, which meets the "Highway and Bridge Wind-resistance Design Standard". The experimental results show that the change of the ventilation rate of the railing can significantly reduce the amplitude of the torsional vortexinduced resonance.

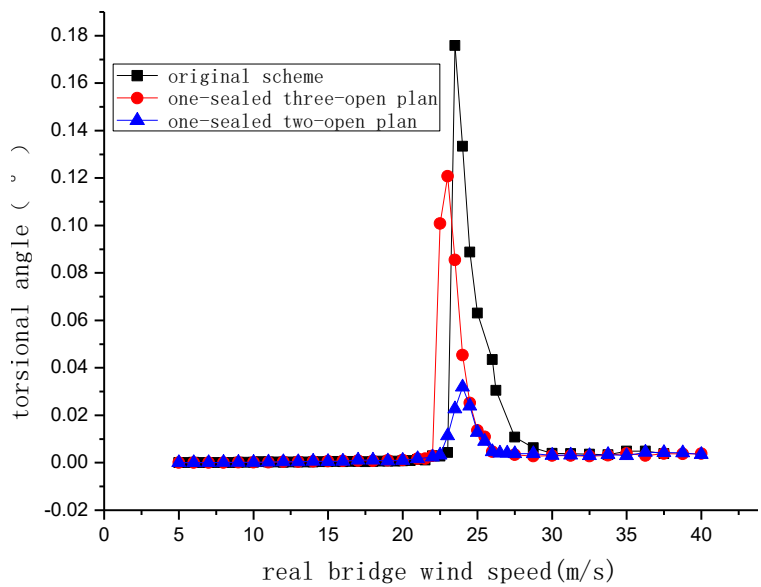

(a) Torsional vortex vibration

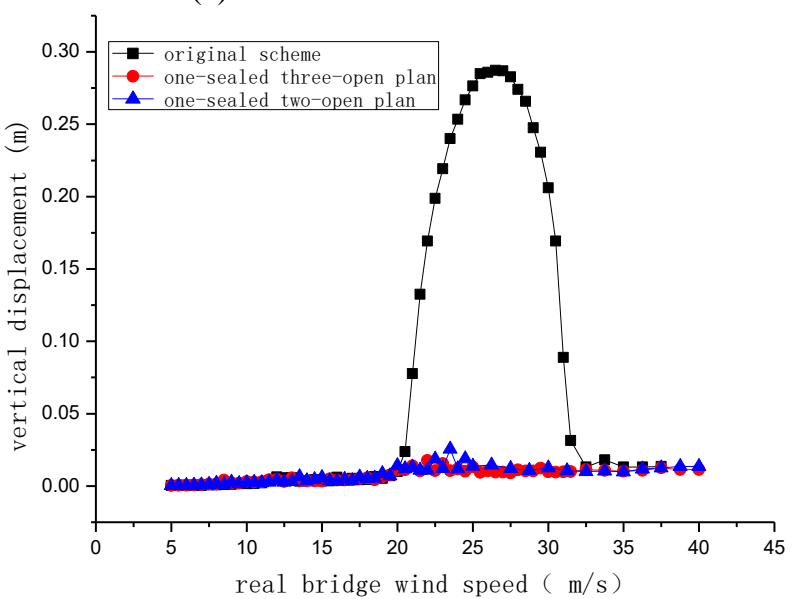

(b) Vertical bending vortex vibration

Figure 5. Relationship between amplitude of vortex vibration and wind speed

Fig. 5 (b) is relationship curve of the vertical displacement and wind speed under the original scheme and the two railing closure plans at the angle of attack of $+5^{\circ}$. The vertical coordinate is the standard deviation of the vertical displacement under the corresponding wind speed. It can be seen from Fig. 5 (b) that there is a significant vertical bending vortex-induced resonance at the angle of attack of $+5^{\circ}$ in the original scheme. When the wind speed of the actual bridge is $26.5 \mathrm{~m} / \mathrm{s}$, the vertical bending amplitude is $0.4061 \mathrm{~m}$, which does not meet the requirements of the "Highway and Bridge Wind-resistance Design Standard". Wind tunnel tests are carried out on the one-sealed three-open plan and one-sealed two-open plan. It can be seen from the figure that no obvious vertical bending vortex-induced resonance appeared in the test wind speed. The test results show that the change of the ventilation rate of the railing can effectively restrain the occurrence of the vertical bending vortex-induced resonance.

Both the one-sealed three-open plan and the one-sealed two-open plan meet the requirements of bridge to flutter stability and aerostatic stability, and no obvious vortexinduced resonances appeared in these two plans at other angle of attack.

\subsection{Pressure distribution [13]}

\subsubsection{Mean pressure coefficient}

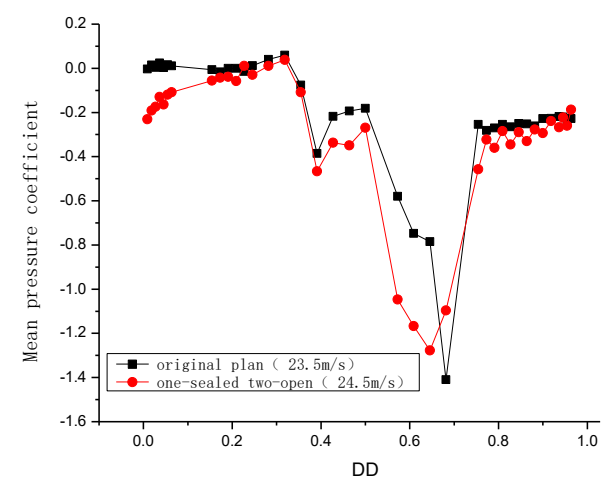

(a) Upper surface

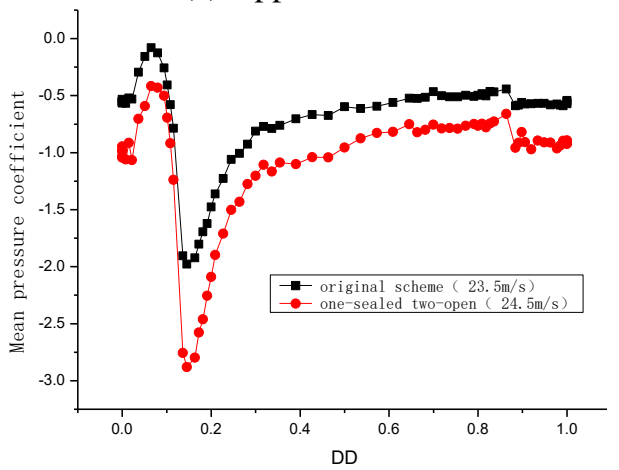

(b) Lower surface

Figure 6. Mean pressure coefficient of the surface of measured points at the wind speed when the torsional vortex vibration amplitude reaches the maximum

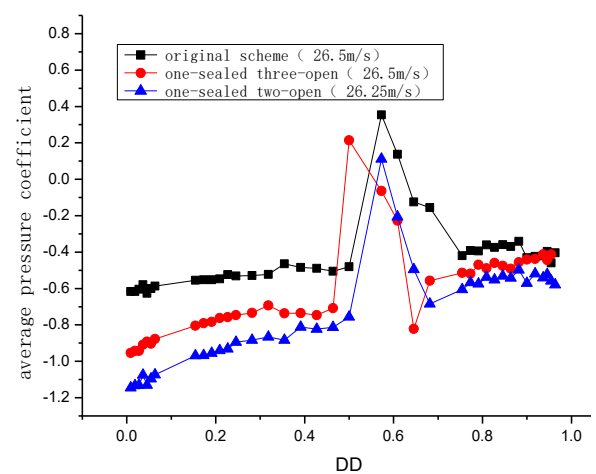

(a) Upper surface

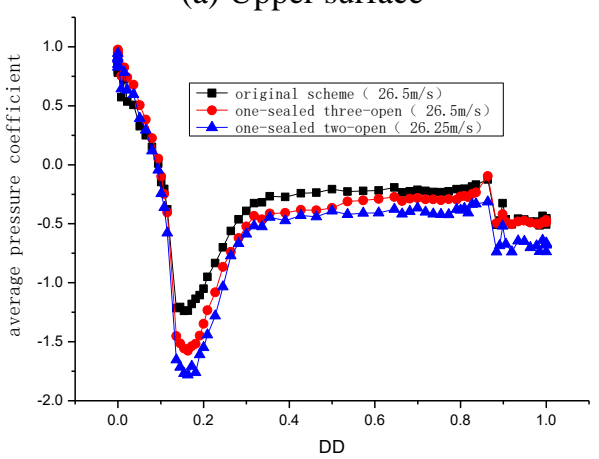

(b) Lower surface

Figure 7. The mean pressure coefficient of the surface of the measured points at the wind speed when the torsional vortexvibration amplitude reaches the maximum 
Fig. 6 and Fig. 7 are the mean pressure coefficients of the measured points on the surface of the model at the wind speed when the torsional and vertical bending vortexvibration amplitude reaches the maximum. Since there are many wrong data in the one-sealed three-open plan at the angle of attack of $-5^{\circ}$, only the pressure coefficients of the original scheme and the one-sealed two-open plan are shown in Figure 6. It can be seen from the diagram that the distribution law of the mean pressure coefficient of the original scheme and the closed railing scheme is consistent, whether it be the torsional vortex vibration or the vertical bending vortex vibration. That is to say, the change of the ventilation rate of the railing does not essentially change the shape of the cross section. However, the mean pressure coefficient increases with the decrease of the ventilation rate of the railing, which is due to the decrease of ventilation rate and the increase of the wind resistance area of the railing. The distribution of the surface pressure coefficient can not explain the influence of the railing ventilation rate on the vortex-induced resonance of the bridge.

\subsubsection{Fluctuating pressure coefficient}

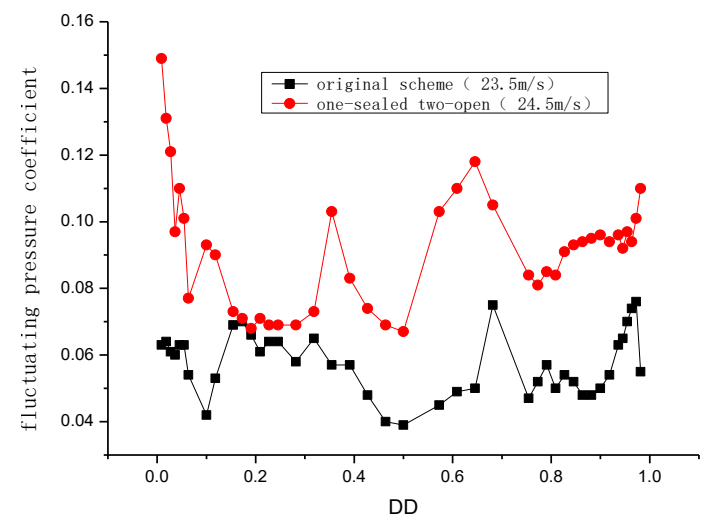

(a) Upper surface

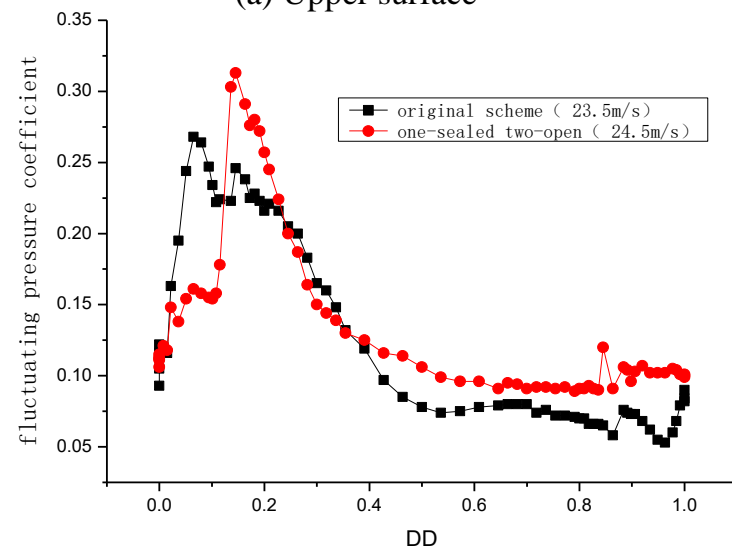

(b) Lower surface

Figure 8. The fluctuating pressure coefficient of the measured points at the wind speed when the torsional vortex vibration amplitude reaches the maximum

Fig. 8 is the fluctuating pressure coefficient of the measured points of the model at the wind speed when the torsional vortex vibration amplitude reaches the maximum. Fig. 5(a) shows clearly that the vortex-induced vibration amplitude in the one-sealed two-open plan is much smaller than the original scheme. But in Fig. 8(a), the fluctuation pressure coefficient on the upper surface of the model in the one-sealed two-open plan is significantly greater than that in the original scheme. Although the change situation of the fluctuating pressure coefficient on the lower surface with the ventilation rate is more complex than the upper surface, it can be seen from Fig. 8(b) that the fluctuating pressure coefficient of the lower surface in the closed railing scheme is still greater than that in the original scheme. The above analysis shows that the fluctuation of the surface pressure at each measuring point of the closed railing scheme model is greater than that of the original scheme.

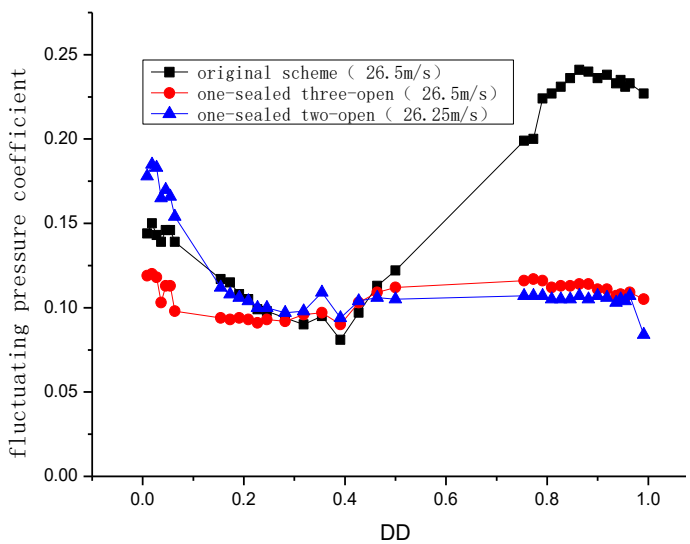

(a) Upper surface

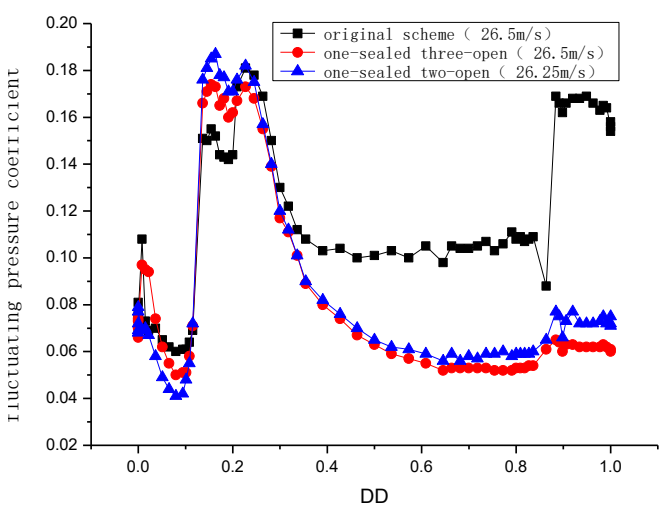

(b) Lower surface

Figure 9. The fluctuating pressure coefficient of the measurement points at the wind speed when the vertical bending vortex-vibration amplitude reaches the maximum

Figure 9 is the fluctuating pressure coefficient of the measured points on the surface of the model at the maximum wind speed when the vertical bending vortex vibration amplitude reaches the maximum. Compared with Fig. 8, the distribution of the fluctuating pressure coefficient of the measuring point is significantly affected by the ventilation rate of the railing. It can be seen from Fig. 9 (a) that the coefficient of fluctuating pressure on the surface of the closed railing scheme model is relatively stable. Especially when $\mathrm{DD}$ is larger than 0.4 , the surface fluctuating pressure coefficients of one-sealed three-open plan and one-sealed two-open plan models are both near 0.1 , while the fluctuating pressure coefficient of the original scheme has a sudden increase after this point. It indicates that there is a larger vortex at the middle and lower reaches of the upper surfaces when the railings are not closed. In Fig. 9(b), the distribution law of fluctuating pressure coefficients of the lower surface in the original scheme is close to that of the closed railing scheme when DD is smaller than 0.3 , and the values are close to each other. But after crossing this point, the fluctuating 
pressure coefficient of the original scheme is obviously larger than that of the closed railing scheme. It indicates that there is also a large vortex at the middle and lower reaches on the lower surface in the original scheme. The fluctuating pressure coefficients of the closed railing scheme and the original scheme have significant difference, but the fluctuating pressure coefficient distribution of one-sealed three-open plan and one-sealed two-open plan are relatively close, and the measured pressure fluctuation is smaller than that of the original scheme.

Through the above analysis, it can be concluded that the size of the fluctuating pressure coefficient is not exactly the same as that of the amplitude of vortex vibration and it is not determined by whether the vortex vibration occurs or not. That is to say, the suppression effect of the vibration suppression measures on vortex induced resonance cannot be judged by the size of fluctuating pressure coefficient.

\subsection{Power spectral (PSD) [14-15]}

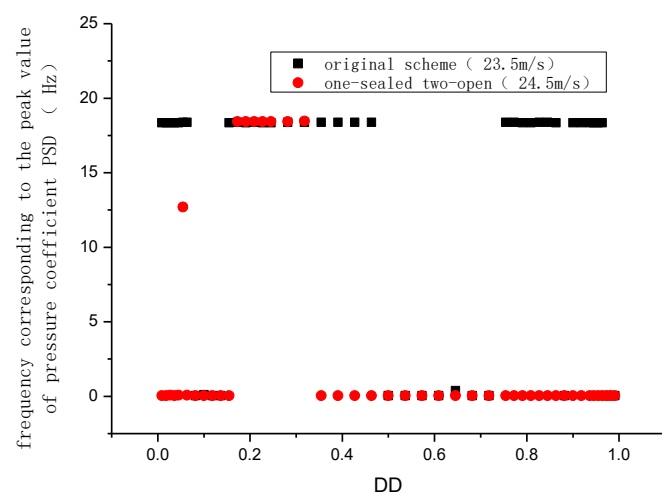

(a) Upper surface

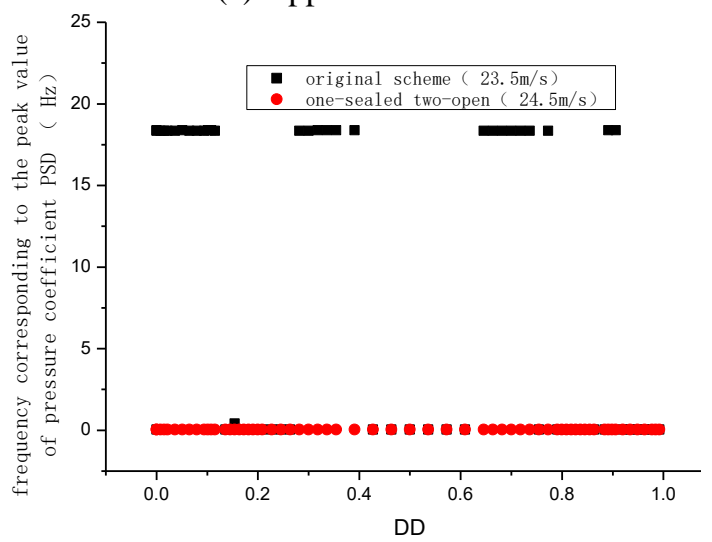

(b) Lower surface

Figure 10. The frequency corresponding to the peak value of pressure coefficient PSD (torsional vortex vibration)

The comparison between the mean pressure coefficients and fluctuating pressure coefficients of the measuring points on the surface of the original scheme model and the closed railing scheme model did not reveal the internal reasons for the impact of the change of railing ventilation rate on the performance of vortex vibration. Therefore, it will be further analyzed next from the perspective of energy. The pressure duration of each measuring point on the model surface contains abundant information, and its spectrum can not only reflect the pulsation frequency characteristics of each measuring point, but also reflect the relationship with the whole vibration.
It can be seen from Fig. 5 (a) that the maximum wind speed when the vortex vibration amplitude of the original scheme reaches the maximum is not the same as the maximum wind speed when the vortex vibration amplitude of the closed railing scheme reaches the maximum. In order to avoid the influence of wind speed on energy, the pressure duration is nondimensionalized, and the power spectrum density of pressure coefficient duration is studied.

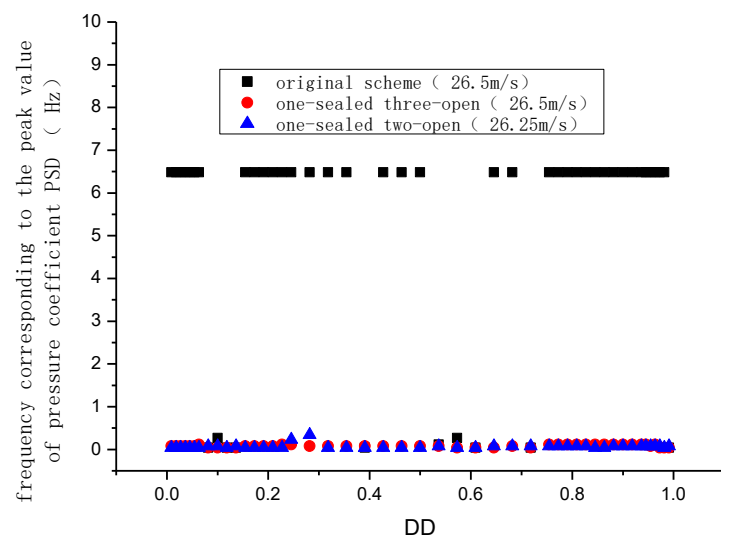

(a) Upper surface

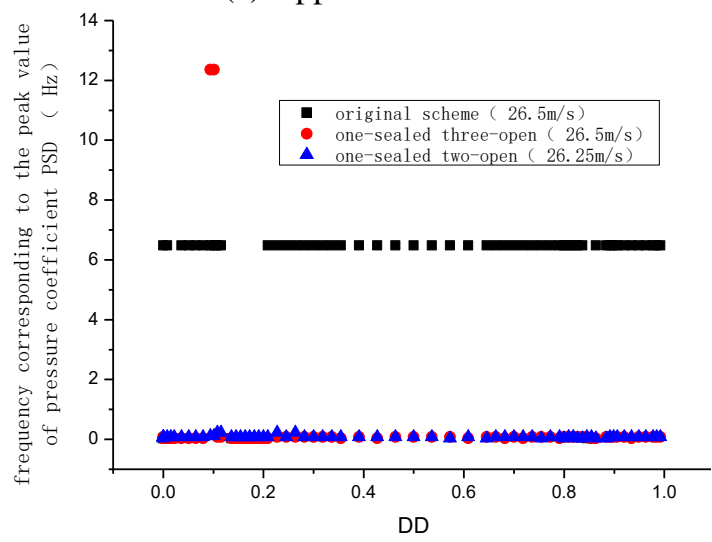

(b) Lower surface

Figure 11. Frequency corresponding to the peak value of pressure coefficient PSD (vertical bending vortex vibration)

Fig. 10 is the frequency corresponding to the peak value of power spectral density of the measuring points at the maximum wind speed when the vortex vibration amplitude reaches the maximum in the original scheme and the onesealed two-open scheme. It can be seen from the diagram that the predominant frequency of most of the measuring points in the original scheme is $18.34 \mathrm{~Hz}$, and is located near the first order torsional frequency of the model. However, the predominant frequency of only a few measuring points on the upper surface of the closed railing scheme are concentrated near the first order torsional frequency. It also explained that the fluctuating pressure coefficient of the closed railing scheme shown in Fig. 8 is relatively larger and that no significant torsional vortex resonance phenomenon is observed in Figure 5. That is to say, the surface pressure fluctuation of the closed railing scheme occurs at a distance away from the first order torsion frequency. This phenomenon explains the internal reason for the influence of the rail ventilation rate on the vortex-induced resonance characteristics of the bridge structure: the decrease of the ventilation rate of the railing changes the frequency of vortex shedding, so that it is far away from the torsional frequency, 
thus weakening the amplitude of vortex vibration or restraining the vortex vibration.

Fig. 11 is the frequency corresponding to the peak value of the power spectral density of the measuring point duration at the maximum wind speed when the vortex vibration amplitude reaches the maximum in the original scheme and the two closed railings schemes. Similar to the rule shown in Fig. 10, the predominant frequencies of most of the measurements in the original scheme are $6.49 \mathrm{~Hz}$, near the first order vertical bending frequency of the model. The predominant frequencies of all measured points of the two closed railing schemes are all $0 \mathrm{~Hz}$, much lower than the vertical bending frequency. The decrease of the ventilation rate of the railing changes the concentration of the energy on the vertical bending frequency, thus inhibiting the occurrence of the vertical bending vortex-induced resonance.

Through comparing Fig. 5 (a) and (b), it is found that the vertical bending vortex-induced resonance is more sensitive to the change of the ventilation rate of the railings than the torsional vortex-induced resonance. In order to study the sensitive threshold of vertical bend vortex-induced resonance to the ventilation rate of railings, the wind tunnel test was carried out through one-sealed five-open scheme and onesealed four-open scheme, and the vortex-induced resonance has not been effectively suppressed. It can be seen that when the ventilation rate of railings reduced by $25 \%$, it is the threshold of its influence on the vertical bending vortexinduced resonance.

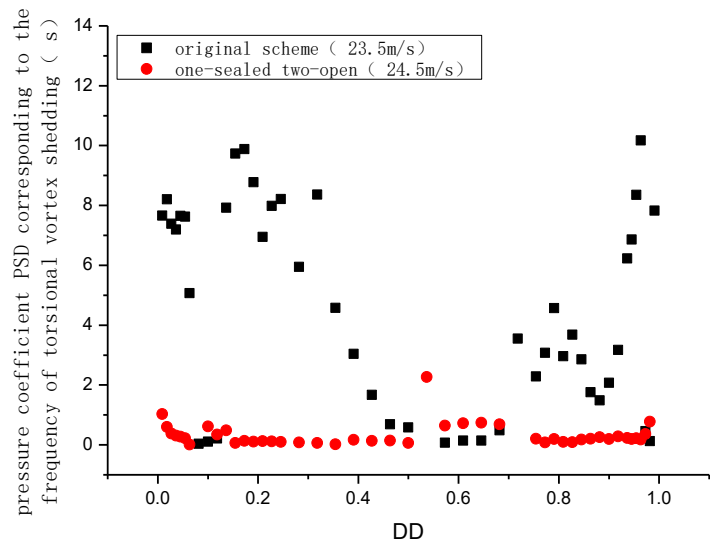

(a) Upper surface

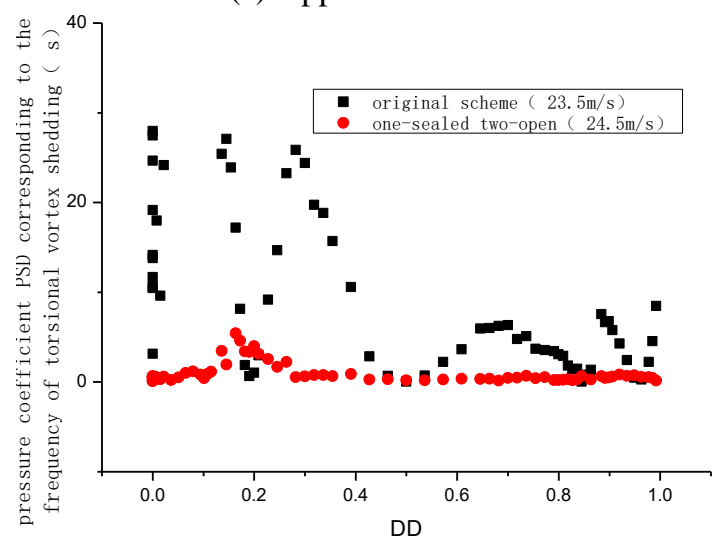

(b) Lower surface

Figure 12. The pressure coefficient PSD of each measuring point corresponding to the frequency of torsional vortex shedding
The energy of each measuring point corresponding to torsion frequency and vertical bending frequency is extracted, such as Fig. 12 and Fig. 13. It can be seen from the diagram that the energy in the measured points in the original scheme concentrated on the model torsion and the vertical bending frequency, which is much larger than that of the closed railing scheme. The larger energy on the first order frequency motivates corresponding vortex-induced resonance, and the energy concentrated on the first order frequency is small in the closed railing program, which is not enough to motivate the vibration of the structure. This is the inherent mechanism to restrain vortex-induced resonance by changing the railing ventilation rate.

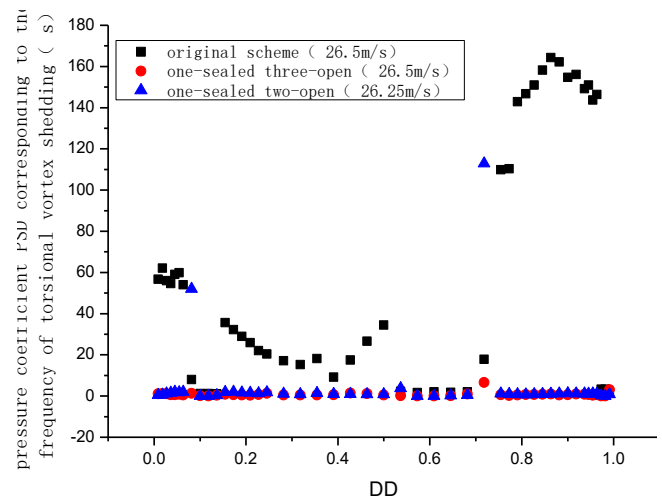

(a) Upper surface

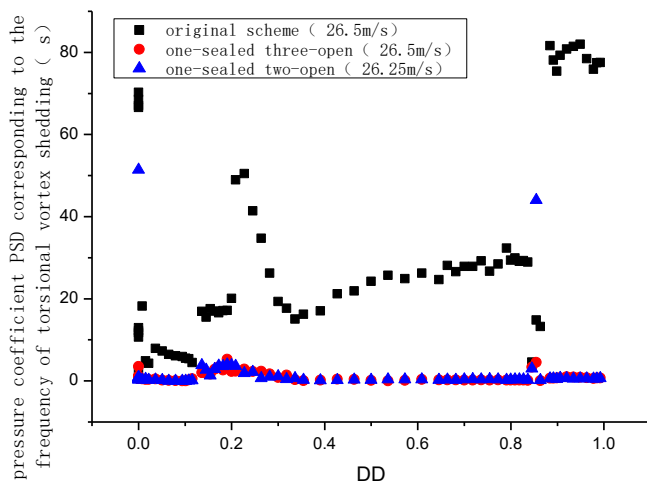

(b) Lower surface

Figure 13. The pressure coefficient PSD of each measuring point corresponding to the frequency of vertical bending vortex shedding

\section{CONCLUSIONS}

Through the wind tunnel test research, the following conclusions can be drawn:

(1) The change of the railing ventilation rate effectively breaks the concentration of the energy of each point on the surface at the first order frequency. So changing the railing ventilation rate can be taken as an effective measure to suppress the occurrence of torsional and vertical bending vortex-induced resonance.

(2) The sensitivities of torsional and vertical bending vortexinduced vibration to the railing ventilation rate are different. When the railing ventilation rate decreases to certain threshold, the vortex-induced resonance can be effectively suppressed. Vertical vortex-induced vibration for railing ventilation rate is more sensitive, when the railing ventilation rate reduced $25 \%$ can effectively suppress the vertical vortex- 
induced vibration, the railing ventilation rate reduced $33 \%$ can effectively limit the torsional vortex-induced vibration. It is suggested that the railings of this bridge should be reduced by $33 \%$ with the one-sealed two-open plan.

(3) The size of fluctuating pressure coefficient can not be used as the basis for judging the occurrence or amplitude of vortex-induced resonance which should be analyzed with the power spectral characteristics.

Changing the ventilation rate of railing can be used as a measure to suppress the vortex-induced of main beam. However, this paper only uses a sealed rule to reduced the ventilation rate of the railings, the influence on vortexinduced vibration characteristics of main beam should be further studied by different sealed rules.

\section{ACKNOWLEDGMENT}

The research is supported by the Key scientific research projects of Universities in Henan (16A560031), the School Doctoral Research Initiation Foundation Project of NorthChina University of Water Resources and Electric Power (40445).

\section{REFERENCES}

[1] Xiang HF, Chen AR, Gu M. (1994). Suppressing the vortex-Excited vibration of bridge with tuned mass damper (TMD). Journal of Tongji University (Natural Science Edition) 22(2): 159-164.

[2] Liu JX. (1995). Vortex-induced vibration and its control in responses of bridge to wind. China Journal of Highway and Transport 8(2): 74-79.

[3] Xiang HF. (2000). Aerodynamic studies of long-span cable-supported bridges in China. Chinese Quarterly of Mechanics 21(4): 393-400.

[4] Zhang W, Wei ZG, Yang YX. (2006). Wind tunnel test of suspension bridge stiffening beam at high reynoldsnumber. The Twelfth National Conference on Structural Wind Engineering, Xi'an, pp. S447-S453.

[5] Goswami I, Scanlan RH, Jones NP. (1993). Vortexinduced vibration of circular cylinderI: Experimental data. Journal of Engineering Mechanics 119(11): 22702287.

[6] Goswami I, Scanlan RH, Jones NP. (1993). Vortexinduced vibration of circular cylinder II: new model. Journal of Engineering Mechanics 119(11): 2288-2302.

[7] Zaoui FZ, Hanifi HA, Abderahman LY, Mustapha MH, Abdelouahed T, Djamel O. (2017). Free vibration analysis of functionally graded beams using a higherorder shear deformation theory. Mathematical Modelling of Engineering Problems 4(1): 7-12.

[8] Yao Y, Geng WB. (2017). Study on flight control of multi - rotor plant protection unmanned aerial vehicle. Academic Journal of Manufacturing Engineering 15(2): 95-100.

[9] Cheng DR, Deng SP, Lu XZ. (2016). Research of hydraulic variable pitch control of the wind turbine based on PID. Academic Journal of Manufacturing Engineering 14(1): 6-11.

[10] Wind-Resistant Design Specification for Highway Bridge (2004). JTG/T D60-01-2004, China.

[11] Li S, Liu DW, Li Q. (2015). The optimal design of a wind tunnel model sting system based on the CFD method. International Journal of Heat and Technology 33(4): 137-144.

[12] Cui X, Li JW, Liu JX. (2010). Experimental Study on vortex resonance of streamline-like bridge deck section. The Eighth China National Conference on Wind Engineering and Industrial Aerodynamics, Yinchuan, pp. S431-S436.

[13] Liu JX, Cui X, Li JW. (2010). Reynolds number effect of surface pressure distribution and strouhal number of a typical bridge deck section. Journal of Vibration and Shock 29(4): 146-149.

[14] Lin GW, Wang XL. (2016). Multi-objective optimal scheduling method for power system based on wind power accommodation. Modelling, Measurement and Control A 89(1): 244-258.

[15] Song J, Chen FY. (2015). Calculation model for thermo-mechanical coupling and 3D numerical simulation for concrete tower of cable-stayed bridge. Mathematical Modelling of Engineering Problems 2(2): 9-12. 